\title{
DEVELOPMENT OF A RETROFIT COAL COMBUSTOR FOR INDUSTRIAL APPLICATIONS
}

\section{TECHNICAL PROGRESS REPORT JANUARY - MARCH 1987

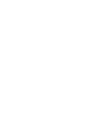

\author{
PREPARED FOR:
}

\author{
U.S. DEPARTMENT OF ENERGY \\ PITTSBURGH ENERGY TECHNOLOGY CENTER
}

DOE CONTRACT DE-AC22-87PC79654

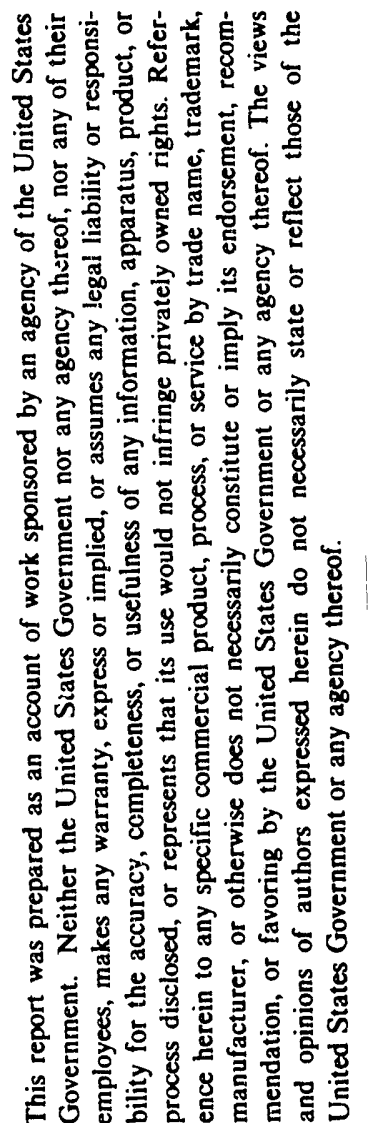

MANAGEMENT AND TECHNICAL CONSULTANTS, INC.

P.O. Box 21. Columbia, Maryland, 21045 (301) 982-1292 Telex 292354 / MTCl UR

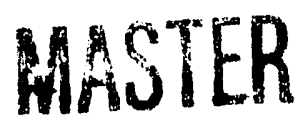

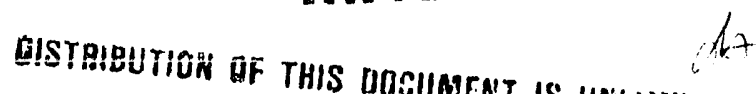




\section{PREFACE}

In this first quarterly technical report for DOE Contract No. DE-AC2287PC79654, a description of the background, technology, and application is provided. This descriptive material will be omitted from subsequent quarterly reports but is incorporated here for completeness of record.

The design and fabrication of advanced combustion chambers were completed during this period. Initial testing on both the bare metal and refractory lined advanced chambers were initiated. The units were tested initially with gas but primarily with coal. A Pittsburgh \#8 pulverized coal was used for these test activities. Both advanced chambers pulsed well. 
1.0 INTRODUCTION . . . . . . . . . . . . . . . . . . . . . . . 1

1.1 APPLICATIONS REQUIREMENTS . . . . . . . . . . . . . 2

1.2 BASIC DESIGN AND OPERATIONAL REQUIREMENTS . . . . . . . 3

2.0 TECHNICAL BACKGROUND . . . . . . . . . . . . . . . . . . 4

2.1 PULSE COMBUSTION DISCUSSION .............. 4

2.2 RETROFIT SYSTEM DISCUSSION . . . . . . . . . . . 6

3.0 PROJECT DESCRIPTION AND WORK STATUS. . . . . . . . . . . . . . 10

3.1 PROJECT DESCRIPTION . . . . . . . . . . . . . 10

3.2 TASK DESCRIPTIONS . . . . . . . . . . . . . . 10

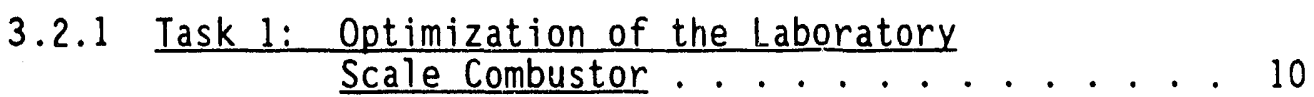

3.2.2 Task 2: Scale-Up Pilot Unit Design . . . . . . 12

3.3 STATUS .................... 12

\subsection{TECHNICAL DISCUSSION OF WORK COMPLETED}

DURING THE REPORTING PERIOD . . . . . . . . . . . . . . . . . . 16

4.1 ADVANCED CHAMBER DESIGN AND FABRICATION . . . . . . . 16

4.1.1 Design .................... 16

4.1.2 Fabrication . . . . . . . . . . . . . 23

4.2 CONFIGURATION OPTIMIZATION TESTING . . . . . . . . . 25

5.0 PLANNED ACTIVITY FOR THE NEXT PERIOD . . . . . . . . . . . . . 33 


\section{LIST OF TABLES}

2-1 COMPARISON OF COMBUSTION GASES PRODUCED BY OIL, GAS AND CWM FUELS . . . . . . . . . . . . . . . . . . . . . . 7

3-1 ANALYSIS OF PITTSBURGH \#8 COAL . . . . . . . . . . . . . . 14

\section{LIST OF FIGURES}

3-1 PROGRAM LOGIC FOR DEVELOPMENT OF A PULSE COAL COMBUSTOR FOR RETROFIT APPLICATIONS .................... 11

3-2 MTCI ADVANCED CHAMBER CONFIGURATION ............ 13

4-1 FLOW CHPRACTERISTICS DURING AIR INTAKE . . . . . . . . . . 17

4-2 FLOW CHARACTERISTICS DURING CHAMBER EXIT . . . . . . . . . 18

4-3 MTCI DIfFUSER BASED AERODYNAMIC VALVE . . . . . . . . . . . 22

4-4 NEW CHAMBER DESIGN .................... 26

4-5 RESONANCE TUBE COOLING SCHEME. . . . . . . . . . . 28

4-6 PHASED COAL INJECTOR .................... . . 29

4-7 MODIFIED HANBY DESIGN PULSE COMBUSTOR . . . . . . . . . . 30

4-8 VENTURI DIODE INSERT ............................... 31

4-9 COAL FEED SYSTEM ..................... 32 
SECTION 1.0

\section{INTRODUCTION}

A large fraction of industrial boilers and process heaters within the industrial sector are fired by petroleum-derived fuels and natural gas. Typical industrial boilers include those that are used in pulp and paper, chemical, petrochemical and textile industries. etc. The total U.S. Watertube and firetube boiler (oil/gas-fired) capacity is in excess of $2.5 \times 10^{12} \mathrm{Btu} / \mathrm{hr}$ (Devitt, et al., EPA, 1979). The overall load factor for this equipment is approximate $1 y$ ' 30 percent. This implies, that the estimated annual consumption of 0 il and gas is in excess of $6.6 \times 10^{15}$ Btu in the U.S. industrial firetube and water tube boiler market. The firing range from $10-100 \mathrm{MMBtu} / \mathrm{hr}$ includes over 40 percent of the deployed capacity in the United States. The market potential for retrofit of coal-based fuels is therefore quite large in this end-use sector, even with a low market capture fraction.

Similarly, data compiled by the American Petroleum Institute (API) (Cherry, 1980) showed that the vast majority ( 94 percent) of process heaters are fired on gaseous fuels. Approximately 69 percent of process heater fuel consumption is refinery gas (varying mixtures of hydrocarbon and hydrogen produced as a by-product of petroleum refining); and approximately 25 percent is $n=t u r a l$ gas. The total refinery gas and natural gas consumption by process heaters is approximately $1.25 \times 10^{15} \mathrm{Btu} / \mathrm{yr}$ with over 40 percent in the form of units rated 10 to $100 \mathrm{MMBtu} / \mathrm{hr}$ input.

In the case of the process heater market, the retrofit potential is contingent upon other factors. First, the bulk of the process heater fuel consumption is in the chemical and petrochemical sector. Second, replacement of refinery gas, which is now being used to fire most of such heaters, will require an increase in the value of the refinery gas over the cost of the retrofit coal-based fuel. This could be expected to occur as the demand for light fractions increase, thus, increasing the need for hydrogen and, in turn, the need for the refinery gas as feedstock to steam reformers. A potentially more attractive industrial process heater market for retrofit applications is the directly fired industrial furnace. This includes cement kilns, certain glass furnaces and direct-fired metal processing furnaces. A primary problem which may be encountered with some of these direct-fired applications is expected to be due to contaminants which emanate from the retrofit combustor and mix with the material being processed. In the case of glass furnaces that consume large amounts of natural gas, particulate matter and sulfur compounds may have undesirable effects on the composition of the glass melt. Glass is usually a very good solvent that dissolves most minerals, resulting in a solid solution when cooled; however, for some ash compositions and high grades of glass, such contaminants may not be tolerated. Low-grade glass containers, on the other hand, can be insensitive to such contamination, particularly with beneficiated coal-based fuels and with slagging first stage combustion that rejects the bulk of the ash upstream of the furnace. 
Similar problems will be encountered regarding other direct-fired industrial furnaces, such as certain cement kilns and metal processing furnaces. These end-use applications are very attractive due to the large market potential and their high energy consumption. The latter is important since the cost of energy is a significant component of the end-product cost and, hence, could result in short recovery period for retrofit costs.

In some of the cases where the contamination problem cannot be tolerated, process modifications may be sought which convert the furnace to an indirectly fired unit. This requires however, that the desired process temperature of the material being processed not be excessively high. This includes some heat-treating furnaces and melting of lower temperature materials (annealing of metals and melting kovars, etc.). The MTCI pulse combustor is well-suited for such applications, since the resonance tube of a pulse combustor can be employed as an efficient radiant heater. In these applications, the resonance tube is made from a ceramic or a high-temperature alloy of thin wall construction and can be configured with large radiant surface area. With this retrofit modification, the exceptionally high heat transfer between the gases in the resonance tube and the tube wall, which is due to the fluctuating flow field and the high effective root mean square film velocity, could eliminate the need for further recuperation from the gases in the exhaust plenum. The latter would otherwise be required due to increased flue gas furnace exit temperatures as a result of the furnace retrofit from a directly fired to an indirectly fired configuration. Clearly, retrofit applications of radiant, indirectly fired heaters to the same configuration are much easier.

While the potential for retrofit in the industrial boiler and some process heater applications is significant, new retrofit combustion equipment is required for burning coal-based fuels. This retrofit equipment must be designed to an acceptable cost in a practical retrofit package. Such a retrofit application must also have a cost recovery period which is attractive to the end-user.

The pulse combustor technology which was developed at the laboratory scale by MTCI offers the potential of being attractive, if not ideal, for retrofit applications of industrial boilers and process heaters in the size range from 10 to $100 \mathrm{MMBtu} / \mathrm{hr}$ firing rate. The attributes of this technology include a compact combustor unit which aspirates its own air and can be designed in a retrofit package which is both cost-effective and operationally attractive.

\subsection{APPLICATION REQUIREMENTS}

Design and operating requirements of industrial oil/gas-fired boilers and process heaters that must be considered in retrofitting coal-based fuel combustors include thermal, physical, operational, and pollution factors. The number of thermal and physical factors that must be considered increases if significant ash carryover occurs from the combustor with high ash content 
fuels. The discussion provided in the two following subsections is focused primarily on all industrial boilers and the special class of process heaters that are used predominantly in the chemical and petrochemical sections. These process heaters are those which are indirectly heated, where the fluids that are being processed are contained in heat exchangers. MTCI had an opportunity to assess the retrofit application aspects of this type of process heater under a previous DOE contractor (DE-AC22-83PC60419) for the retrofit of pulse combustors fired with CWM. The material contained herein is extracted from the results of this effort.

\subsection{BASIC DESIGN AND OPERATIONAL REQUIREMENTS}

The basic design and operational factors that must be considered in retrofitting coal-based fuel combustors to $0 i 1 /$ gas-fired boilers and process heaters include thermal, physical, operational and emission control requirements for the total system. The thermal requirements of the system being retrofitted or replaced are of primary importance. Thermal factors that must be considered include furnace heat release, furnace absorption, furnace exit temperature, gas velocity in the convective banks and flue gas exit temperature.

Furnace heat release requirements dictate that the combustor be sized to deliver the rate of heat input per square foot of cooling surface for which the furnace is designed. Furnace absorption is closely related to "urnace heat release but also requires that the combination of gas inlet temperature and the amount of heat delivered to the furnace walls match the conditions for which the unit is designed. It is especially important that excessive wall heat fiux not be developed anywhere in the furnace since this situation can result in damage to tubes and, in the case of a process heater, degradation of the process fluid. Design heat release and heat absorption rates generally are much higher for industrial boilers than for process heaters. The determining factors in limiting the heat flux for which a furnace can be designed are usually the fluid vapor pressure characteristics, operating pressure and thermal sensitivity of the fluid. The designers must avoid overheating the fluid to the point where its vapor pressure too closely approaches its operating pressure. In that case, film boiling can occur and lead to tube metal overheat, or thermal degradation of the fluid can occur. Industrial boilers operate over a wide range of pressures, from low-pressure, saturated steam producers, to large field-erected units which drive steam turbines. Process heaters are generally low-pressure units.

The furnace exit temperature is a critical design parameter in industrial boilers where furnace heat release rates are sufficiently high to develop high exit gas temperatures and particularly where superheat of the working fluid is involved. In these cases, the design must not permit the furnace exit temperature to exceed capabilities of the first superheater. Maximum tube metal temperature limits are normally placed at $1000^{\circ} \mathrm{F}$, the safe working temperature limit of the best superheater alloys within a reasonable price range. For process heaters the furnace exit temperature is generally well below critical limits due to the lower heat release rates used for furnace design. 
SECTION 2.0

\section{TECHNICAL BACKGROUND}

Pulse combustion achieves high combustion efficiency, deep staging, high turndown and high sulfur capture efficiency. Sulfur removal is achieved by injecting dry sorbent. In addition, these combustors aspirate their own combustion air and provide pressure boost and the associated exit gas kinetic energy. This energy can be employed to reject particulate matter from the combustor effluent with little to no system pressure drop penalty. The aerodynamic design of a properly designed pulse unit will induce oscillations that can achieve these benefits in a simple, compact and self-regulating combustor package without the need for a complex collection of subsystems.

\subsection{PULSE COMBUSTION DISCUSSION}

The intrinsic stoichiometry of a pulse combustor can be fixed by design and will remain relatively constant over a wide range of firing rates. At the lower end of this firing rate range, the combustion-induced pressure fluctuation in the chamber is lower. Therefore, the amount of air intake induced by the fluidic diode (the aerodynamic valve), coupled with the inertial effects of the hot gas column in the resonance tube, is lower. When the fuel feed rate is increased, the amplitude of the pressure fluctuations is increased due to the increase in the heat release responsible for excitation of the combustion-induced dynamic pressure. This, in turn, induces more air intake. The combustor operating stoichiometry is, therefore, automatically maintained over a range of firing without the need to actively control and coordinate the combustion air and fuel mass flow rates. The range of firing for which the operating stoichiometry can be maintained is a function of the combustor design, particularly the aerodynamic valve and the geometry of the chamber transition region from the chamber inlet to its maximum diameter. With deep staging (substoichiometric air), the range firing rate is reduced somewhat. With air stoichiometry between 0.7 and 2.0 , the fuel firing rate range covers approximately a $4: 1$ turndown ratio.

At the low firing rate, the heat release rate in Btu/ $\mathrm{ft}^{3}-\mathrm{hr}$ is lower due to the lower oscillating flow field in the combustor. As the fuel feed rate is increased, the increase in the pressure fluctuation causes a corresponding increase in the fuel burn rate and a correspondingly higher heat release rate. Therefore, the reduction in residence time due to the overall increase in mass flow rates passing through the combustor is accompanied by an increase in the burn rate of the coal particles. This tends to maintain the combustion efficiency of a properly designed combustor substantially constant over the design operating range.

The primary function of the aerodynamic valve is to act as a fluidic diode which employs pressure fluctuations in the combustion chamber for inducing the intake of the combustion air. There are two engineering design parameters that dominate the design of an aerodynamic valve size, the minimum 
resistance to air intake and the fluidic diodicity of the valve. The latter is a non-dimensional ratio between the resistance to flow out of the chamber to the resistance to flow into the chamber (intake). In general, the higher the fluid diodicity of the aerodynamic valve, the more air per Btu/hr of fuel firing is induced by the intake. He should note that a combustor which would normally operate with high excess air, by virtue of employing a valve with high fluidic diodicity, can be operated at lower air stoichiometry by throttling the air intake at a plenum inlet. With a fixed damper setting at the inlet to the plenum, the combustor firing rate can be varied with the induced stoichiometry remaining essentially constant for a range of firing.

It is also possible to reduce the lowest firing rate of a combustor by reduction of both the aerodynamic valve and the resonance tube minimum diameter. This also enhances the start-up characteristics of the combustor. With this design option, the turndown ratio could be greater than $8: 1$. This, however, may require an inlet air fan if the pressure drop for ash removal and flow of the gases through the equipment being retrofitted (boiler, etc.) requires it. Nevertheless, the air intake (mass flow rate) remains dependent on the firing rate since the self-aspiration and boost pressure contribution of the pulse combustor unit remains in effect. This system configuration tends to increase the maximum combustion intensity achievable for two reasons. First, with the higher flow resistance at both ends of the chamber, more dynamic pressure amplitude is obtained. Secondly, on air intake the presence of an air fan tends to allow "supercharging" of the combustor to higher firing rates than are attainable under atmospheric aspirating conditions.

The geometry of the combustion chamber can be selected to afiect the fraction of the fuel burn which contributes to inducing the pressure oscillations and the fraction which is burned down stream from the dynamic pressure peak region under the influence of the induced oscillatory flow conditions. The chamber geometry also affects the sen itivity to method and location of fuel injection as well as to changes in fuel characteristics. The burn rate in the combustion chamber is dominated by vortices which are shed from the transitions in the cross-sectional area of the chamber. In the resonance tube, however, the burn rate is dominated by the axial, oscillating, flow velocity component which tends to increase monotonically from the resonance tube inlet to the exit. The combustion process in the resonance tube is mostly responsible for completing the burn of char produced from the larger particles which are volatilized and partially burned upstream in the chamber. The increase in the oscillating velocity along the resonance tube maintains a high rate of char burn as the char particles become more prone to entrainment and as the $0_{2}$ partial pressure decreases. In all other combustion systems, the relative motion between the gases and the solids is dependent on swirl, turbulence, etc. These flow fields tend to get damped downstream in the flame where they are needed most, i.e., as the char particles become smaller, ash-laden and entrainment-prone, and as the partial pressure of oxygen decreases.

The design of the resonance tube could involve more complex generators in principle, but in MTCI's experience, this is not necessary; i.e., a straight line generator forming a conical section is quite practical. This degree of freedom allows control of the gas exit velocity and the overall volume of the 
resonance tube for a given length. The gas exit velocity is selected such that it is sufficiently high to induce the second stage air or disentrain solids, and simultaneously, sufficiently low to allow good mixing for the second stage burn in staged combustion. The volume of the resonance tube affects both the resistance time available for completing the burn of char produced from larger particles as well as the resonant frequency of the unit.

The pulse combustor design flexibility is uniquely suited for retrofit applications. The degrees of freedom available permit the design and mass production of these simple-to-manufacture, compact burners for retrofit of a wide spectrum of end-use applications.

\subsection{RETROFIT SYSTEM DISCUSSION}

The retrofit applications of CWM-fired pulse combustors which are being considered include industrial boilers and process heaters. Each have critical design and operational constraints associated with them that must be considered in the design of the pulse combustor retrofit system. There are four major requirements: thermal, physical, operational and pollution control, which must be considered in design and operation of boilers and process heaters.

Regardless of the type of equipment to which it is applied, a CWM-fired pulse combustor must first of all meet the basic thermal requirements of the furnace and convective sections. The furnace will generally be designed for a specified heat flux profile, normally characterized by a maximum heat flux in the flame zone, with the flux relaxing to a lower value at the furnace outlet. producing an acceptable heat flux profile in the furnace necessitates achieving a proper combination of initial gas temperature, radiant emissivity of the gas, and gas residence time in the furnace. Table 2-1 compares calculated values of combustion gas quantities and compositions for natural gas, residual oil and CWM fuels. Typical analyses of the three fuels were assumed in the calculations. Combustion of al1 three fuels was arbitrarily assumed to occur at 15 percent excess air. As shown in the table, combustion as from the selected CWM is not substantially different from that produced by $0 i 1$ and gas firing in terms of volume or composition.

The initial temperatures of combustion gases from oil and gas firing are comparable -. i.e., essentially the adiabatic flame temperatures. 0il flames are, however, much more luminous (higher emissivity) than gas flames, which results in their radiating a larger portion of the heat released to the furnace walls and producing a lower furnace-exit gas temperature than gas flames. CWM firing in a pulse combustor produces a lower initial temperature at the furnace entrance than oil or gas firing because a portion of the heat is required for water evaporation before the combustion gas reaches the furnace. Also, the CWM furnace-inlet gas may be essentially non-luminous if the combustion has been completed in the combustor (no combustion staging). In retrofit cases, there may be a tendency for the furnace to receive heat flux slightly below design. This can be partially compensated for by 
TABLE 2-1:

COMPARISON OF COMBUSTION GASES PRODUCED BY OIL, GAS, AND CWM FUELS

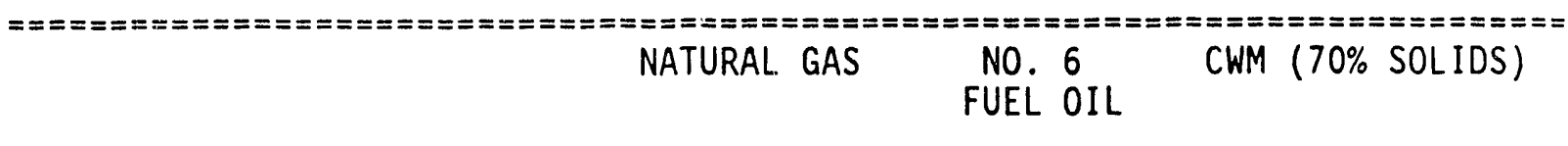

TYPICAL ANALYSIS (wt. \%):

Sulfur

Hyrdogen

Carbon

Nitrogen

Oxygen

Ash, wt. \%

Moisture, wt. \%

HIGHER HEATING VALUE, Btu/lb

SLURRY WATER, 1b/100 ib fuel

COMBUSTION GAS COMPOSITION*

(volume \%):
$\mathrm{SO}_{2}$

$\mathrm{N}_{2}$

$\mathrm{O}_{2}$

$\mathrm{H}_{2} \mathrm{O}$

GAS VOLUME, 1b-moles $/ 10^{6} \mathrm{Btu}$

GAS WEIGHT, 1b/106 Btu

$\mathrm{ASH}, 1 \mathrm{~b} / 10^{6} \mathrm{Btu}$

$\mathrm{SO}_{2}, 1 \mathrm{~b} / 10^{6} \mathrm{Btu}$

\begin{tabular}{r}
0 \\
22.68 \\
69.26 \\
8.06 \\
0 \\
0 \\
0 \\
\hdashline$\ldots$ \\
100.00
\end{tabular}

21,800

0
2.1

10.75

87.9

0

0

0.25

0

100.00

18,200

0
2.2

4.8

72.8

1.5

6.2

9.0

3.5

100.00

13,080

42.85

$\begin{array}{rcc}0 & 0.112 & 0.158 \\ 8.33 & 12.52 & 13.90 \\ 71.58 & 74.29 & 70.78 \\ 2.47 & 2.58 & 2.45 \\ 17.60 & 10.50 & 12.71\end{array}$

31.74

32.24

33.33

878

938

970

0

0.137

6.88

0

2.32

3.38

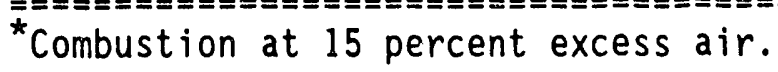


admitting the combustion gas lower in the furnace than is practical with conventional burners. Also, the combustor design can be staged so that the second (burn-out) stage occurs in the furnace, thereby, generating flame luminosity to meet the required heat-transfer characteristics of the furnace cavity. The tendency toward lower overall furnace heat flux would clearly minimize the threat of locally overfluxing the furnace wall, which is generally a serious concern with any furnace modification for coal firing, especially for process heater applications.

The thermal requirements of the convective section of the boiler or process heater are generally met if the combustion gas from the furnace enters at or near the design conditions of temperature, flow rate and composition. This will result in the correct amount of overall convective heat transfer and will achieve the final temperature requirement of the working fluid. It is particularly important that the gas temperature be near its design value in the vicinity of the finishing section of the heat transfer surface, where the final fluid temperature is achieved. Too low a gas temperature at this location will result in the specified fluid temperature not being met, and too high a gas temperature at this location can result in overheating and damaging the tube metal.

As indicated in Table 2-1, differences in gas weight, volume and composition produced by CWM firing versus 0 il/gas firing are not major. Therefore, in retrofitting CWM to 0 il/gas equipment, the thermal requirements of the convective section will be met if the furnace-exit gas temperature is sufficiently near the design point. Generally, achieving the design heat absorption to the furnace walls will produce a furnace exit gas temperature near design. However, some consideration must be given the heat used to evaporate water from CWM fuel, combustor heat losses or cooling requirements, if any as well as the slight differences in gas weight and composition.

Although one of the capabilities of the pulse CWM combustor is to achieve very high levels of ash rejection, significant levels of ash carryover to the furnace and convective section may potentially be permitted for some applications. If this proves to be the case, several additional design constraints must be considered. Foremost among these is maintaining a furnace-exit gas temperature at least $100^{\circ} \mathrm{F}$ below the ash softening point. Failure to achieve this could lead to fouling problems in the convective section. If significant ash carryover proves to be the design selected for certain retrofit applications, the combustor integration should be designed for adequate heat removal to produce a sufficiently low furnace-exit temperature at full load. Boilers producing saturated steam or steam with relatively low superheat (most industrial boilers) will be more forgiving of a lowered furnace-exit temperature and may already operate at sufficiently low furnace-exit temperatures for most coal ashes. Process heaters are typically designed for furnace-exit temperatures in the 1400-1600 $\mathrm{F}$ range, and should thus pose no difficulty in this regard.

With significant ash carryover from the combustor, several other factors pertaining to convective section operation must also be considered. Coal units are usually designed for 80 fps or less maximum gas velocity in the convective section. Tube spacings are wider and tube bank depths, more 
limited, for coal firing than for oil/gas firing. The limitation placed on gas velocity could lead to serious derating of $0 i 1 /$ gas units in converting to coal. However, the scaled pulse CWM combustor is expected to reject 99 percent or more of the coal ash, which should greatly alleviate the velocity restrictions used for normal coal firing. Furthermore, the pulse combustor will efficiently reject the large end of the ash particle size spectrum thus further reducing the expected erosion potential of ash particles on the convective tubes. Depending upon the amount of slas rejection achieved and the size range of the ash particulate carryover, little or no derating may be required. Similarly, the relatively wide tube spacings used for ordinary pulverized coal firing may be unnecessary for pulse CWM firing.

In addition, pulse combustors are compact devices that achieve high heat release rates. This is a coroliary of the ability of the fluctuating flow pattern to maintain disentrainment of the burning particles. The boundary layer of combustion products are swept away from the burning solid, thus providing access to oxygen at the least possible diffusion impedance. Pulse combustors can achieve up to $6 \mathrm{MMBtu} / \mathrm{hr}^{-\mathrm{ft}^{3}}$ with gaseous fuels and a MMBtu/ $\mathrm{hr}-\mathrm{ft}^{3}$ with CWM's. The cyclone combustor is limited to the order of 1 to 2 MMBtu/hr-ft ${ }^{3}$.

Pulse combustors, therefore, provide a compact burner system which is suitable for use in retrofit applications. It is also important to note that in the size range of interest, pulse combustors are not limited bj the constraints and difficulties encountered in scaling down the alternative, advanced combusters that were originally intended for utility applications. 
SECTION 3.0

PROGRAM DESCRIPTION AND WORK STATUS

\subsection{PROGRAM DESCRIPTION}

The objective of this phase of the program for the development of a retrofit pulse coal combustor for industrial applications is to design, fabricate, test and evaluate advanced chamber designs at the laboratory scale utilizing several fuels (Task 1). The activities are structured to provide design criteria for scaling up to the pilot-scale level for the demonstration of a pulse combustor fired with coal-water mixtures for industrial boiler and process heater retrofit applications. The program logic is depicted in Figure $3-1$.

The design data and information acquired during Task 1 of the initial phase will be used to develop scale-up design criteria for scaling the laboratory-scale design to pilot-scale including interface requirements for the field demonstration. The scale-up pilot unit design will be sufficiently developed to allow fabrication of the unit for testing in the existing test facility upon DOE exercising its option for the follow-on activities of this program. These follow-on activities will include the fabrication, test and engineering evaluation of the pilot-scale combustor and include technical and laboratory test support activities for reducing the technical risks and costs of de relopment at the pilot-scale. Based on the information, test, data and technical support activities, a retrofit combustor system will be designed for field demonstration as shown on the left in Figure 3-1.

At the end of this phase of the program, a design for a retrofit combustor system for field demonstration will be completed with the exception of site-specific design details which will be provided after approval for the field demonstration at the subcontractor test site.

\subsection{TASK DESCRIPTIONS}

\subsubsection{Task 1: Optimization of the Laboratory-Scale Combustor}

The specific objectives of this task are to optimize the chamber design of the feasibility units developed under Contract No. DE-AC22-83PC60419 for optimized performance with coal and coal-water slurry fuels and to reduce performance sensitivity to variations in fuel specifications.

To meet these objectives, two advanced combustion chamber configurations will be designed and fabricated at the laboratory-scale (1 - 2 MMBtu/hr) size. Design options will include both bare metal and refractory-lined units to permit both air-cooled and adiabatic operation. These advanced designs will 


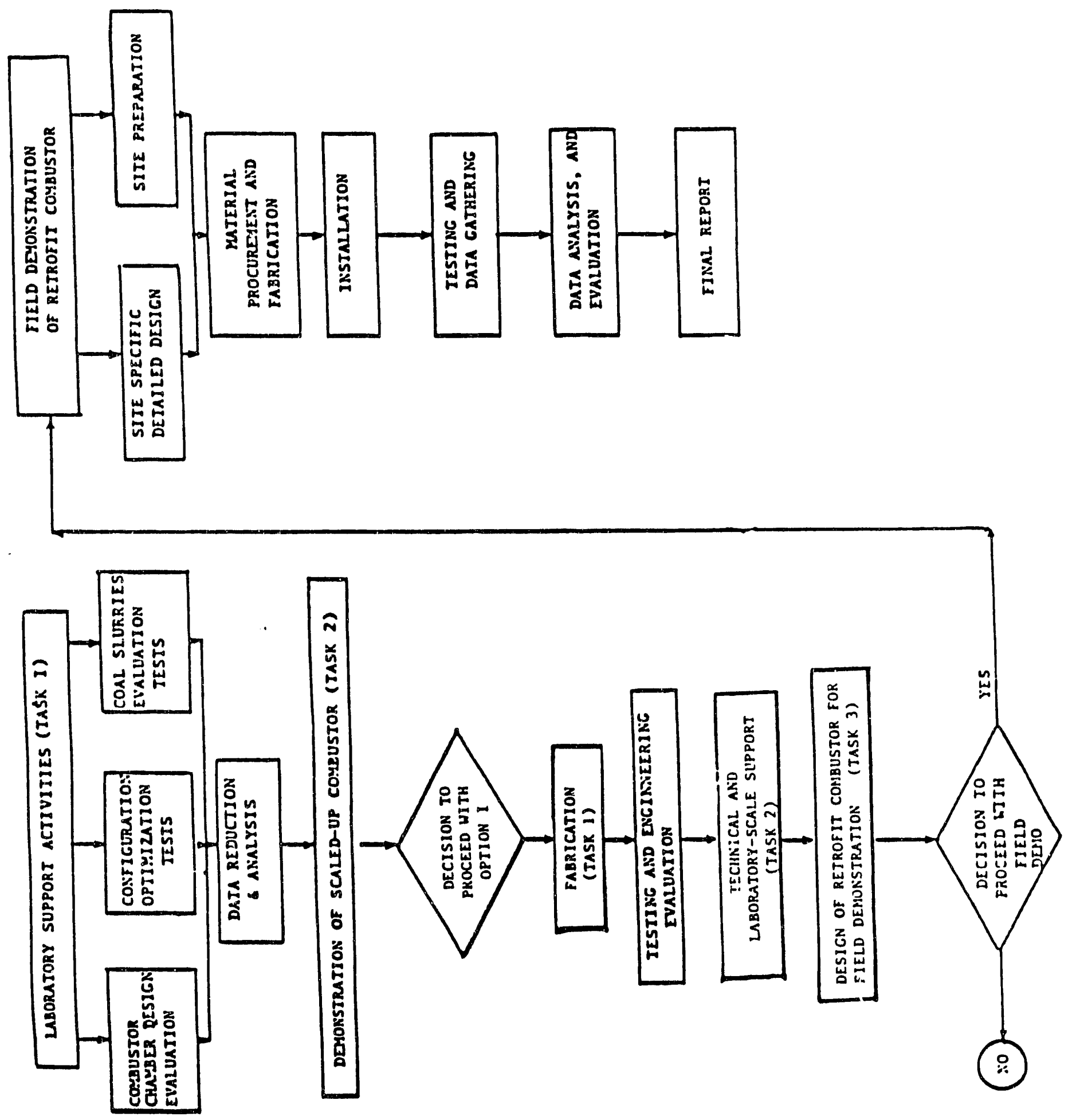

FIGURE 3-1

PROGRAY LOGIC FOR DEVELOPAENT OF A PULSE

COAL COMBUSTOR FOR RETROFIT APPLICATIONS 
be fabricated and then tested to evaluate the performance with respect to the following parameters:

- Combustion intensity and heat release rates,

- Staging capability,

- Dry sulfur capture and ash rejection performance,

- Carbon burnout efficiency,

$0 \quad \mathrm{NO}_{\mathrm{X}}$ emissions performance, and

0 Sensitivity to changes in fuel specifications.

Refractory-lined combustor tests will be conducted employing both the feasibility unit chamber design and one of the advanced chamber designs selected on the basis of the evaluation tests.

\subsubsection{Task 2: Scale-Up Pilot Unit Design}

The specific objective of Task 2 is to design a pilot-scale test unit for evaluation in the existing HirCI facility. To meet this objective, the data acquired under Task 1 will be utilized to develop design scale-up criteria for scaling the laboratory-scale design to pilot-scale. These criteria include consideration of the effect of scale-up on combustor operating frequency, firing intensity (in MMBtu/hr cu.ft.), and the intensity of pressure fluctuation with increased firing rate. The scale-up design also considers all the interface requirements of the pilot-scale development activities at the subcontractor test site. The design developed will be sufficiently detailed to permit the fabrication of the unit when approved by DOE.

\subsection{STATUS}

The design and fabrication of the advanced chambers was completed during this quarter. A bare metal unit in RA 330 stainless steel, and a refractory chamber in two sections each were fabricated. The overall chamber length was 14.1 inches and the maximum diameter was 9.2 inches. Figure 3-2 depicts the shape of the chamber. Total volume of the chamber is 336 cubic inches. Both the bare metal and the refractory-lined advanced chambers were test-fired. The bare metal unit was initially tested with gas, whereas the refractorylined unit was tested with gas and coal. These chambers pulsed very well.

During this reporting period, testing of the Advanced Refractory Chamber (ARC) was carried out for ten days with disassembling, inspection and reassembling of the chamber, tail pipe, secondary combustion chamber and quench tank between tests. Pulverized Pittsburgh \#8 coal was used for most of the tests. The analysis of the pulverized coal sample is presented in Table 3-1 along with the micronized coal used. These coal samples were obtained from KVB Inc. There was some difference between the samples with respect to the ash content, but the main difference was the particle size distribution. The micronized coal has an average size of ten microns, with a narrow distribution, whereas the pulverized coal is 80 percent through 100 mesh (150 microns). The average particle size is approximately 50 microns with a broad distribution. 


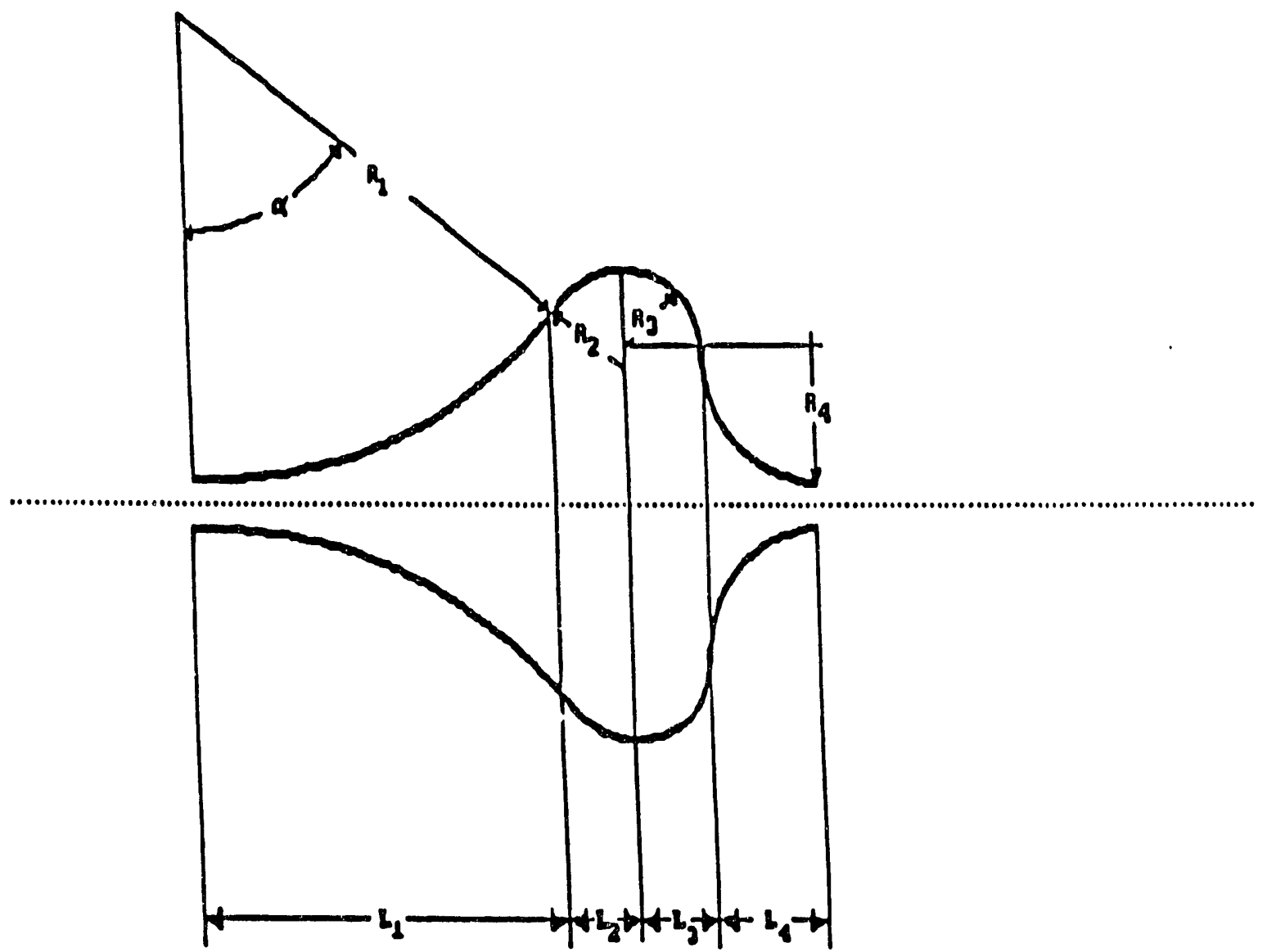

FICURE 3-2

ATCI ADVANCED CHAMBER CONFIGURATION 
.ABLE 3-1: AMALYSIS OF PITTSBURGH 18 COAL

\begin{tabular}{|c|c|c|c|c|}
\hline \multirow{2}{*}{$\begin{array}{l}\text { SAMPLE DATA } \\
\text { SIZE } \\
\text { PROXIMATE ANALYSIS }\end{array}$} & \multicolumn{2}{|c|}{$\begin{array}{l}\text { APRIL } 1982 \\
\text { MICRONIZED }\end{array}$} & \multicolumn{2}{|c|}{$\begin{array}{l}\text { JULY } 1984 \\
\text { PULVERIZED }\end{array}$} \\
\hline & AS RECEIVED & DRY BASIS & AS RECEJUED & DRY \\
\hline $\begin{array}{l}\text { Moisture } \\
\text { Ash } \\
\text { Volatile } \\
\text { Fixed Carbon }\end{array}$ & $\begin{array}{r}1.62 \\
12.99 \\
37.64 \\
47.75 \\
100.00\end{array}$ & $\begin{array}{r}x \times X X \\
13.20 \\
38.26 \\
48.54 \\
100.00\end{array}$ & $\begin{array}{r}3.4 \% \\
9.28 \\
42.43 \\
44.81\end{array}$ & $\begin{array}{r}x \times x X \\
9.61 \\
43.96 \\
46.43\end{array}$ \\
\hline $\begin{array}{l}\text {HHV, Btu/lb } \\
\text { Alk. as } \mathrm{Na}_{2} \mathrm{O}\end{array}$ & $\begin{array}{l}12650 \\
\ldots\end{array}$ & $\begin{array}{r}12858 \\
0.22\end{array}$ & 12734 & 13193 \\
\hline WLIIMAIE ANALYSIS ZWt & AS RECEIVED & DRY BASIS & AS RECEIYED & $\mathrm{DRY}$ \\
\hline $\begin{array}{l}\text { Moisture } \\
\text { Carbon }\end{array}$ & $\begin{array}{r}1.62 \\
70.00\end{array}$ & $\begin{array}{r}x \times x x \\
71.15\end{array}$ & $\begin{array}{r}3.48 \\
70.86\end{array}$ & $\begin{array}{r}x \times x x \\
73.42\end{array}$ \\
\hline $\begin{array}{l}\text { Hydrogen } \\
\text { Nitrogen } \\
\text { Chlorine } \\
\text { Sulfur } \\
\text { Ash } \\
\text { Oxygen (diff) }\end{array}$ & $\begin{array}{r}4.90 \\
1.23 \\
0.14 \\
2.43 \\
12.99 \\
6.69 \\
100.00\end{array}$ & $\begin{array}{r}4.98 \\
1.25 \\
0.14 \\
2.47 \\
13.20 \\
6.81 \\
100.00\end{array}$ & $\begin{array}{r}5.23 \\
1.28 \\
0.22 \\
0.41 \\
9.28 \\
9.23 \\
100.00\end{array}$ & $\begin{array}{r}5.42 \\
1.31 \\
0.23 \\
0.42 \\
9.61 \\
9.56 \\
100.00\end{array}$ \\
\hline
\end{tabular}

\section{SULEUR FORMS}

Pyritic Sulfur

Sulfate Sulfur

Organic Sulfur

1.56

0.01

1.59

0.86

0.87

EUSION IEMPERATURE OF ASH

REDUCING

OXIDIZING

Initial Deformation

Softening $(H=W)$

Softening $(\mathrm{H}=1 / 2 \mathrm{~W})$

Fluid

$2150^{\circ} \mathrm{F}$

$2550^{\circ} \mathrm{F}$

$2600^{\circ} \mathrm{F}$

$2700^{\circ} \mathrm{F}$

$$
\begin{array}{r}
25500^{\circ} F \\
2700+{ }^{O F} \\
2700+{ }^{\circ} \\
2700+{ }^{\circ} F
\end{array}
$$

Silica Value

Base: Acid Ratio

73.67

0.26

$2600^{\circ} \mathrm{F}$

MINERAL ANALSIS OF ASH

Silica, $\mathrm{SiO}_{2}$

Alumina, $\mathrm{Al}_{2} \mathrm{O}_{3}$

Titania, $\mathrm{THO}_{2}$

Ferric Oxide, $\mathrm{Fe}_{2} \mathrm{O}_{3}$

Lime, CaO

Magnesta, MgO

Potassium Oxide, $\mathrm{K}_{2} \mathrm{O}$

Sodium Oxide, $\mathrm{Na}_{2} \mathrm{O}$

Sulfur Trioxide, $\mathrm{SO}_{3}$

Phos. Pentoxide, $\mathrm{P}_{2} \mathrm{O}_{5}$
Stront tum Oxide, Sro

Barium Oxide, $\mathrm{BaO}$

Manganese Oxide, $\mathrm{Mn}_{3} \mathrm{O}_{4}$

Undeterwined

Fouling Index

Slagging Index

\section{₹ WEIGHI IGNITED BASIS}

50.37

25.59

1.12

16.78

0.68

0.54

2.12

0.29

0.56

0.09

0.01

0.08

0.00

$\frac{1.77}{100.00}$

0.08

0.64 
Initially, the bare metal Advanced Chamber was down-fired with gas, whereas the ARC was fired horizontally with coal. When the ARC was examined, a slag coating was found all around the walls. There was more of the slag at the bottom (about 3/4" thick) than at the top (about 1/2" thick). The ARC was then down-fired to determine whether the slag would flow down, rather than collect in the chamber. In one of the tests when the tail pipe was also refractory-lined, slag dripped down into the cyclone second stage. Most of the time, thick slag coatings were found in the chamber and in the straight section of the tail pipe and not much of the slag was found in the expanding section of the tail pipe. A lot of brown ash was found in the second stage cyclone combustor.

After vertical down-firing tests started, it appeared that the slag layer in the chamber was not growing with time. The slag seemed to melt and dissolve the alumina refractory to a certain extent, as indicated by the chamber diameter remaining constant instead of decreasing due to build up of slag. The slag seemed to be about 1/2" thick, whereas the "white" refractory thickness seemed to have decreased correspondingly to keep the chamber diameter constant. 


\section{SECTION 4.0}

\section{TECHNICAL DISCUSSION OF WORK COMPLETED DURING THE REPORTING PERIOD}

This section discusses the technical results of the work completed during the period December 22, 1986 through April 5, 1987. The technical discussion during this period is primarily associated with the design of the advanced chambers. Although testing of both the bare metal and refractory-lined chambers was initiated during the period, the test data reduction and evaluation for these initial tests was not completed so that discussions for combustor test operation are based on visual observations made during disassembly and reinstallation of the units during this initial test period.

\subsection{ADVA: IED CHAMBER DESIGN AND FABRICATION}

This program is being implemented in parallel with a companion program for the development of a residential applications system. Both programs started with the development experience of a nominal $1.5 \mathrm{MMBtu} / \mathrm{hr}$ feasibility unit which was developed under DOE/PETC contract number DE-AC22-83PC60419. In scaling the design for the residential unit, a decision was made to maintain the basic design the same so that the only variable being the scale-down to the residential size. The initial investigation of advanced chamber configurations, however, was implemented at a $1 \mathrm{MMBtu} / \mathrm{hr}$ nominal size combustor design. The chamber development work at the $1 \mathrm{MMBtu} / \mathrm{hr}$ firing rate would later be used for both systems as appropriate. In the following a presentation of the advanced chamber design and fabrication is provided.

\subsubsection{Design}

An advanced chamber design optimized for pulse coal combustion evolved as a result of the developmental test experience to date. The general design configuration is shown in Figure 3-2. The objective of this design is to employ quadratic form generators that are used to define an axisymmetric chamber in order to accommodate a number of design and chamber performance attributes. At this stage, the quadratic form generators were chosen to be simple arcs of a circle as depicted in that figure.

In order to discuss the design and performance attributes of the advanced chamber configuration, chamber flow characteristics during the relevant portions of both air intake and chamber exhaust are depicted in Figures 4-1 and $4-2$, respectively. 


\section{copalcs riLE \\ M187-04. art}

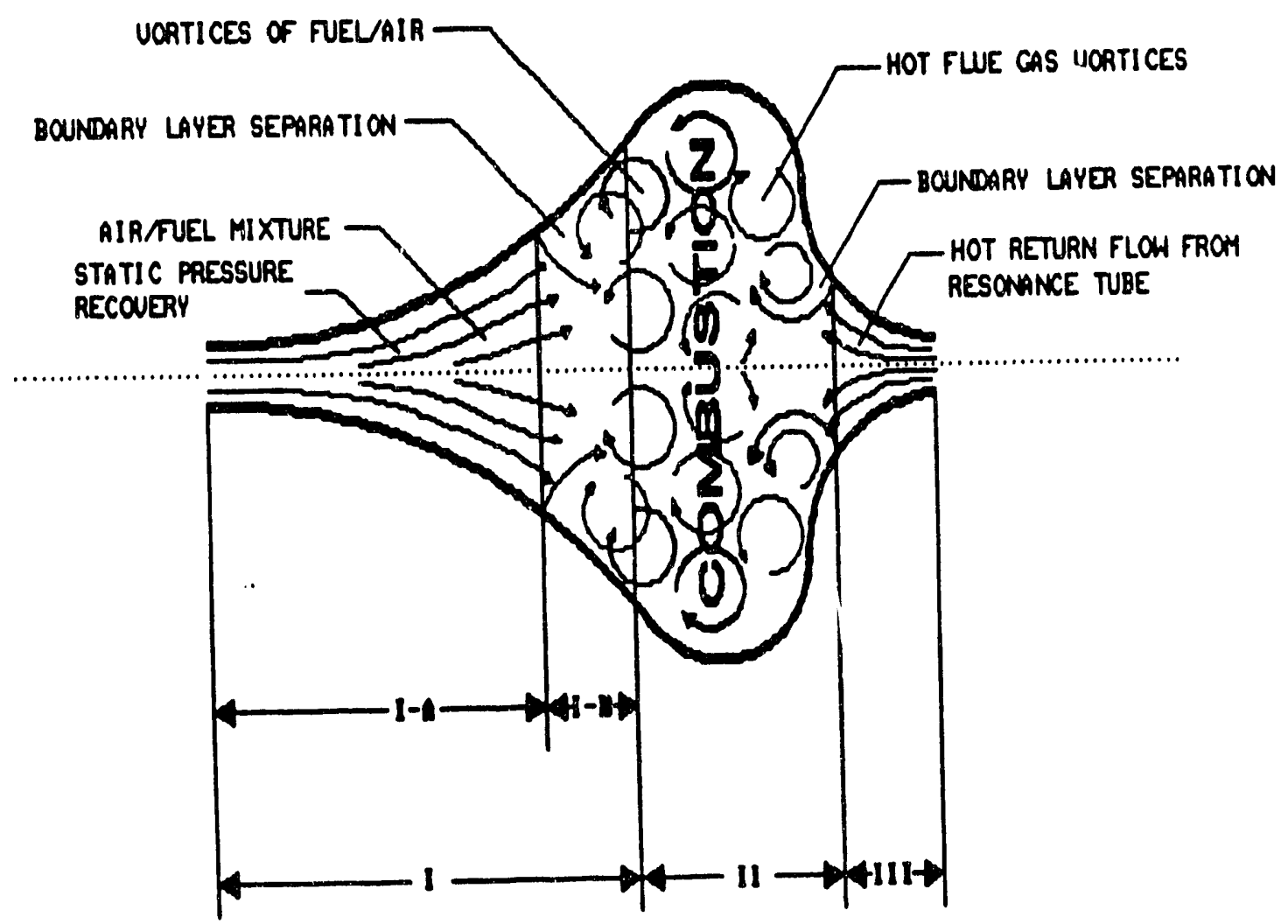

FIGURB 4-1: RON CRARACTERISTICS DURING AIR IMTARE 


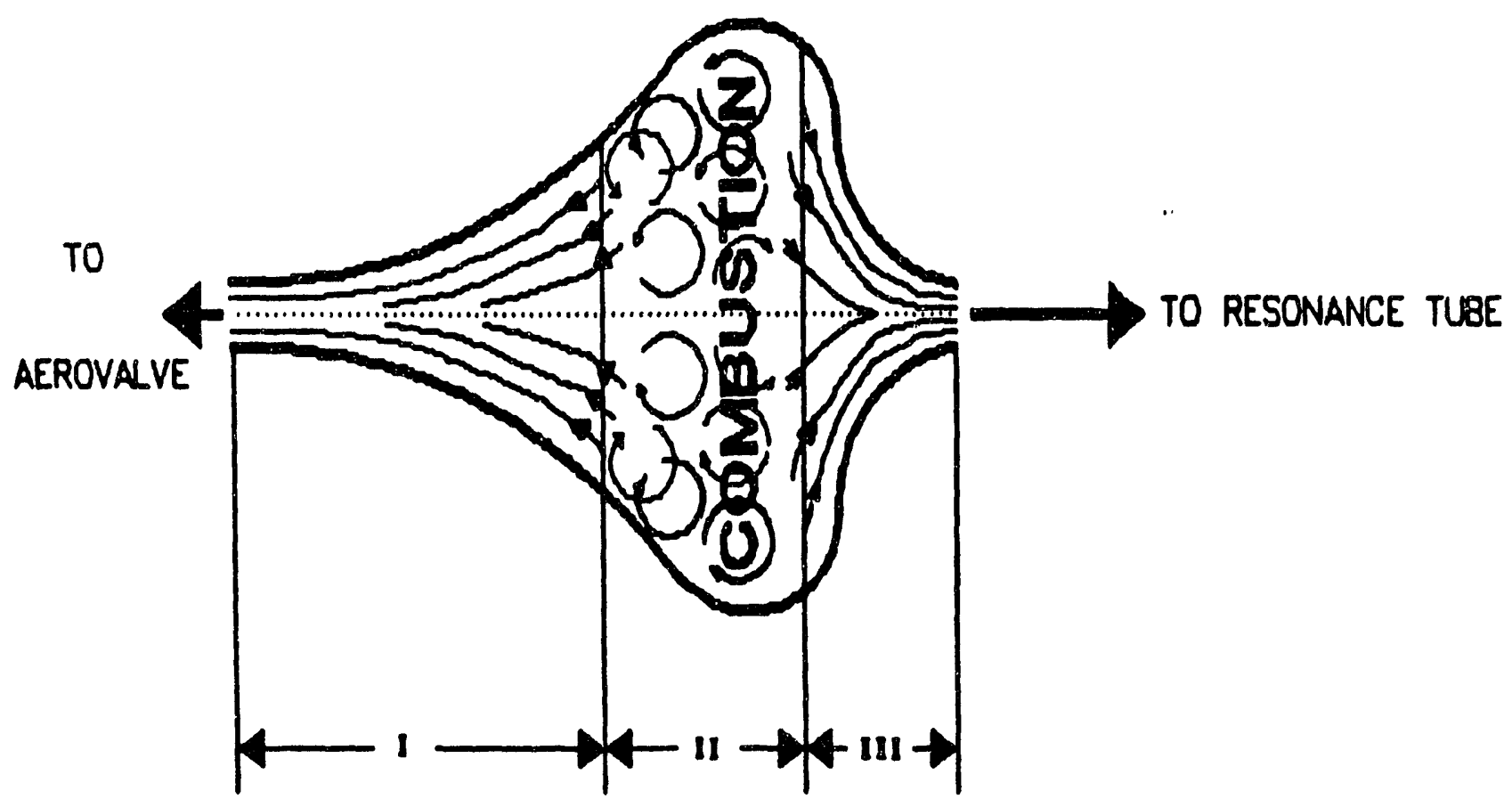

FIGURE 4-2: TLN CRARACTERISTICS DURING CRAYRBR BXIT 
During air intake, the chamber volume is subdivided into three regions. Region I is further subdivided into subregions I-A and I-B. In subregion I-A, the air flow entering the combustion chamber is retarded in a shallow diffuser section. The reduction in the mean flow velocity is, therefore, achieved with efficient static pressure recovery. This persists until the rate of change in the chamber's cross-sectional area becomes sufficiently large to cause flow separation and, in turn, give rise to vortex shedding as shown at the start of subregion I-B. Retarding the flow with efficient pressure recovery in subregion I-A is aimed at serving two functions. First, the static pressure at the boundary between subregions I-A and I-B will be higher than the static pressure at the inlet to the chamber. Therefore, for a given negative pressure in subregion I-B and region II (the mechanism by which a pulse combustor rechargas with air), the negative pressure at the inlet during air intake will be even lower. The net effect is that the recharge with combustion air will be as if the negative pressure in the chamber is inducing combustion air flow from an intake which has a cross-sectional area equal to that of the boundary between subregions I-A and I-B. This would enhance the inducement of combustion air in the chamber on intake but with high resistance to exhaust flow, as will be discussed below using Figure 4-1. Second, the fuel which is usually injected near the chamber air intake, is provided with more residence time in the flow which is being retarded in subregion I-A and is also exposed to back radiation from the chamber walls and the combustion zone (depicted as region II). This allows some fuel preheat and conditioning for rapid combustion down stream.

In subregion I-B, where shedding of vortices is initiated, vigorous mixing of the fuel and the induced combustion air takes place. In this design, the chamber configuration is employed to achieve mixing instead of the use of a bluff body or a flame holder in the chamber that were used in some conventional and pulse combustors by others in the past. Using a bluff body or a flame holder is not attractive due to the attendant material, life and reliability problems which may be encountered at the chamber operating conditions (high temperature and intense acoustic field). Achieving the proper mixing through proper design of the chamber configuration, instead of using bluff bodies and flame holders, simplifies the combustor design and reduces the manufacturing costs.

An added advantage to the design configuration of region I is the potential for the reduction in the combustor performance sensitivity to variations in fuel specifications. Variation in fuel specification affect the fuel preheat requirements and the flame speed. These differences between oil, gaseous and coal-based fuels are significant. But even within coal-based fuels, variables such as the type of coal, volatile content, char reactivity, particle size distribution and moisture content will affect the required fuel preheat and flame speed at the ignition region. The diverging chamber cross-section between the inlet and the combustion zone provides for monotonic decrease in the mean flow velocity. This, in turn, provides for a zone in which the flame front can stabilize in a short distance along the combustion chamber axis (subregion I-B). This expectation is based on our test experience with conic and quadratic transition regions between the aerodynamic valve and the old cylindrical chamber designs used in our previous work (DE-AC22-83PC60419). In these tests, the sensitivity to fuel injection 
location and method of injection was reduced with quadratic form generators. Similar design considerations enter into the design of a burner throat in the case of conventional burners.

The bulk of the chamber volume is comprised of region II, the combustion region. In this region, the mean flow velocity is at its lowest level within the chamber due to the large cross-sectional area. This is intended to force the release of most of the heat near the dynamic peak pressure zone in the combustor and hence enhance the pressure fluctuations (which incidently further intensifies the heat release rate) per $\mathrm{Btu} / \mathrm{hr} \mathrm{ft}^{3}$ of firing rate. The objective of this is to improve combustion efficiency over a wider range of turn down or deep combustion staging conditions with complete carbon conversion. This design is also intended to provide for an expanded product line for less tooling and manufacturing costs. The combustion chamber volume can be increased significantly by adding a short cylindrical spool section at the maximum chamber diameter without significantly changing the general flow characteristics in the chamber. Therefore, a range of firing rates can be accommodated readily with the same quadratic form generated parts to suit the application requirements. These chambers would then be used with the appropriate tail pipes and aerodynamic valves.

The shape of the chamber in region III and near the region II/ region III interface is designed to enhance auto-ignition and control the magnitude of flue gas return from the resonance tube. The low pressure within the chamber, which induces the combustion air intake, ultimately causes a reverse flow to occur in the resonance tube, with some hot flue gases returning to the chamber.

The returning hot flue gases are rapidly retarded in region II with a very rapid increase in the chamber cross-section (in the returning flow direction). This intentionally inefficient diffuser section results in rapid flow separation and the shedding of hot flue gas vortices that travel upstream in the combustion chamber (toward the chamber's air inlet). This vortex pattern of hot flue gases meets the forward moving vortex pattern of combustion air and fuel mixture within the combustion zone. This, together with the back radiation from the chamber walls, provides for autoignition. The design of the portion of the chamber near the exit is also important to the combustor performance in turn-down and deep staging while maintaining complete carbon conversion. Excessive amounts of resonance tube return flow hinders the chamber's ability to recharge with combustion air and dilutes the gases in the combustion chamber.

As the chamber pressure rises due to combustion, the products of combustion move towards both the resonance tube and the aerodynamic valve. In region I of Figure 4-2, the flow is monotonically accelerated due to the monotonic reduction in the chamber's cross-sectional area in the direction of flow. This, in turn, causes the static pressure to drop until it reaches a minimum at the chamber's air inlet. The aerodynamic valve further impedes the return flow as discussed below.

In region III, the hot gases are made to accelerate very rapidly due to the rapid reduction in the chamber's cross-sectional area in the direction of 
the flow. The diffuser length is very short and the flow acceleration is maintained high, thus causing the boundary layer thickness to remain small in that region with reduced resistance to forward flow. The stream-lines in region III poses significant curvature as the flow accelerates towards the resonance tube exiting the chamber. The centrifugal and large linear acceleration of the flow in this region causes larger size coal particles to lag the flow due to their inertia. Ash particles and small coal particles would preferentially be entrained with the flow to the resonance tube. This is due to the larger surface-to-mass ratio of the ash and smaller size coal particles. The smaller size coal particles are further burned downstream in the resonance tube in the monotonically increasing oscillating velocity amplitude. Sufficiently large coal particles lag behind and are retained in the chamber until the next recharge and are hence exposed to the next combustion cycle. Thus, one of the objectives of the rapid transition between the large maximum chamber diameter and the significantly smaller chamber exit (to tail pipe) diameter, is to provide a preferential dynamic trap for the larger coal particles and retain them in the chamber until they burn to a smaller size.

A further illustration of the diodic effect of the chamber's inlet and exit diffusers using the attributes of the diffuser-based aerodynamic valve design employed by MTCI is presented. The MTCI diffuser-based aerodynamic valve design is delineated in Figure 4-3. In this design, two simple (conic section) diffuser sections comprise the aerodynamic valve. At the inlet, a steep diffuser angle is used which can be between $40^{\circ}$ and $60^{\circ}$ (half cone angle). On the combustion chamber side, a generous shallow angle diffuser is used to provide for efficient pressure recovery $\left(4^{\circ}\right.$ to $\left.7^{\circ}\right)$. The length of the diffuser sections and the minimum aerodynamic valve diameter are selected to meet the combustor integration and performance requirements. Through these variables the overall fluidic diodicity and minimum recharge resistance for a given mean flow rate can be modified. Upon air intake, the flow characteristics are shown in the upper part labeled Forward Flow. In both parts, the chamber is located on the right-hand side of the aerodynamic valve.

During air intake, the boundary layer build-up, which is monotonic in the direction of the flow, is compensated for by the diverging cross-sectional area of the shallow diffuser section (right-hand side). The intake stream lines also draw from a large area near the valve intake since there is no flow separation on intake from the steep diffuser because of the flow acceleration from a large to a narrow cross-section.

On exhaust of hot gases from the chamber, the flow characteristics are shown in the lower part of Figure 4-3, labeled Reverse Flow. As depicted in the figure, the boundary layer build-up over the length of the shallow angle diffuser in the direction of flow, together with the diffuser angle, cause the effective minimum diameter to be small. Flow is then separated from the steep angle diffuser with reverse flow causing the stream lines to remain within a small cross-sectional area for exhaust. 

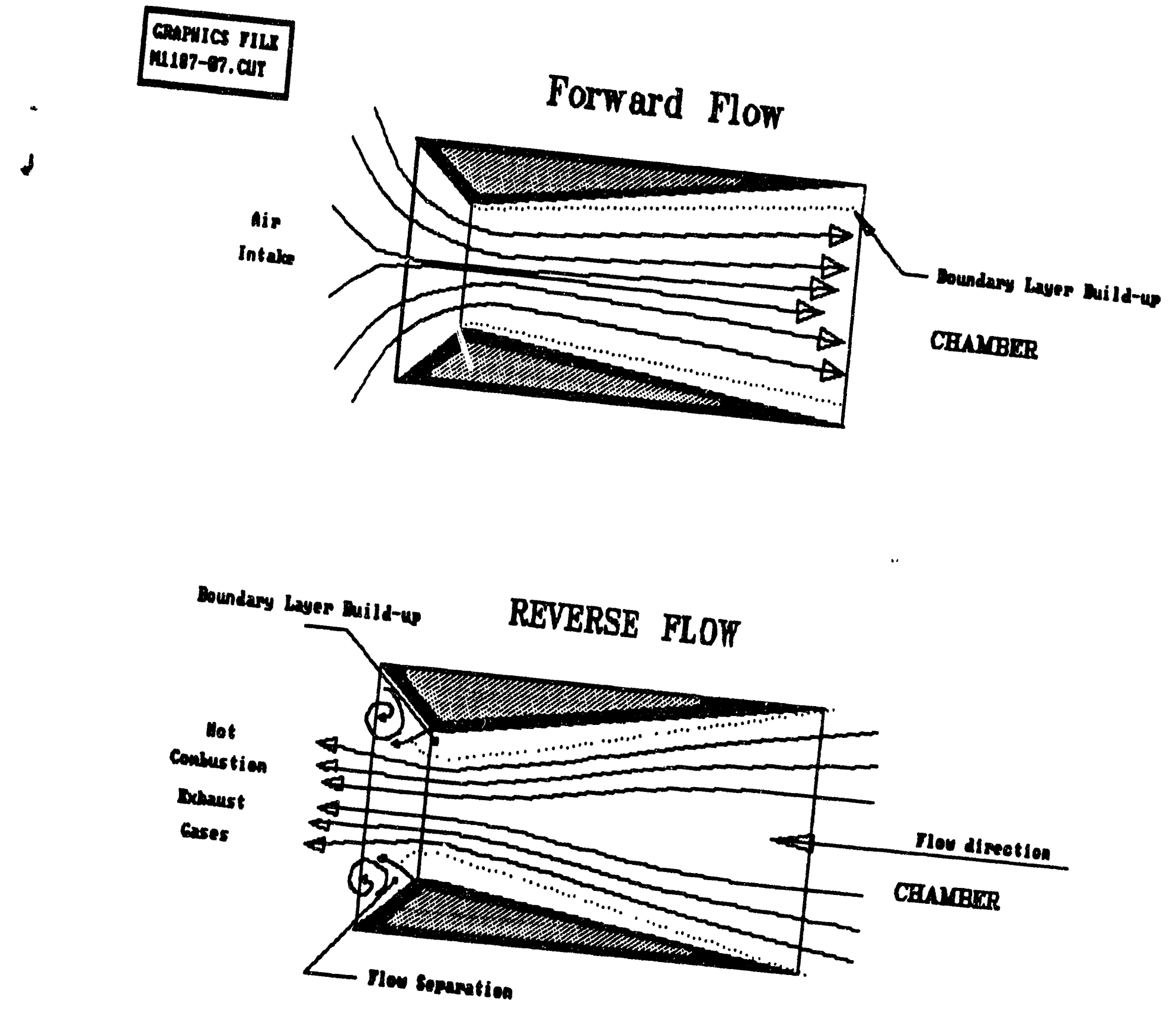

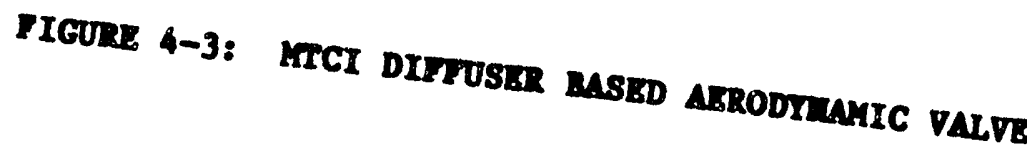

10024/DE-AC22-87PC79654

22

ER11-24Q.01/79654-101 
In addition to the above, the temperature of the air on intake is significantly lower than the temperature of hot gases from the chamber durinj reverse flow. This in tirn causes the mass density of the incoming air to be higner and the viscosity to be lower than their counter parts for the hot gases leaving the chamber.

Boin the flow cliaracteristics and the difference in temperature between the intake air and $:$ : chamber reverse flow gases give rise to the aerodynamic valve fluidic diodicily.

With the fluctuating pressure in the chamber, the fluidic diodicity of the aerodynamic valve causes the net flow at the aerodynamic valve to be intake of combustion air at a self-induced level of stoichiometry.

The flow characteristics in regions $I$ and III of the chamber, as shown in Figures 4-1 and 4-2, are similar to those described for the aerodynamic valve. This similarity results in flow diodicity, which supplements that of the aerodynamic valve.

The test of the advanced chamber design will be devoted to experimental development of optimum chamber configurations. The need for more complex quadratic form generatore is not anticipated. However, the relative values for $R_{1}$ through $R_{4}$ will be changed during the investigation.

\subsubsection{Fabrication}

Methods of fabrication of advanced chamber configurations having quadratic form gerierators were investigated during this reporting period. This included the design and fabrication of both refractory lined and bare metal components for the industrial combustors. The approaches evaluated included:

1. Bare metal units fabricated from off-the-shelf parts available in siainless steel supply catalogs.

2. Metal spirining of specially designed quadratic form shapes.

3. Machining of mandrels having specially designed quadratic form generators to be used for casting refractory lined components.

Considerations were made to the needs of both the laboratory developmental test program and the manufacturing issues for the commercial configuration system. A. primary consideration for the test program is the speed by which modificatiuns could he made and the cost of implementation. The primary considerations for manufacturing are the cost of manufacturing and the ability to maintain optimum design configurations without compromise to performance.

1. Bare Metal Units Fabricated From Standard Parts. With the small size of the experimental pulse combustor, the possibility of using standard, off-the-the-shelf stainless steel parts represents an option. Standard parts 
which include tubing, bell reducers, conical reducers, etc., could be welded and, as appropriate, flanged to fabricate the pulse combustor units. This approach is quite attractive for laboratory test activities, particularly at the exploratory stage of a wide spectrum of design configurations and when one or two units need to be fabricated in a short time for test purposes. The cost of such components is moderate and most parts should be readily available.

This approach, however, will constrain the configurations and the combustor designs that can be explored since bare metal standard shapes are the building blocks. This may also result in constraining the scope of the developmental test program to bare metal components (chambers, tail pipes, etc.) which are also limited in configuration flexibility. A review of the available stainless steel off-the-shelf components was made to assess the availability of appropriate shapes, material properties and thickness, etc., and to explore the costs. As a result, this approach was rejected (as the primary approach for combustor fabrication) for the following reasons:

$i$ - In pulse combustion, the acoustic, fluidic and aerodynamic characteristics of the combustor configuration dictate performance. Therefore, constraints on design configurations at this stage are unacceptable.

ii - Tests with refractory lined chambers and tail pipes are required to complete the scope of investigation.

iij - The cost of the off-the-shelf parts was not all that attrictive and delivery times for complex geometries from some suppliers was unacceptably long, i.e., it seemed that these parts were made as special orders even though they were in the catalog, which reflected in both delivery time and cost.

iv - More design modifications and tests may be required to converge on the commercial configuration units which would ultimately be specially manufactured anyway.

It was, therefore, decided to explore the following two approaches for fabrication of advanced combustor configurations.

2. Metal Spinning. Another approach to fabrication of flexible component and combustor configuration is metal spinning. In this approach, a mandrel is machined and metal is spun to form the desired axisymmetric shapes. In this approach, significant flexibility is available for the component. shapes including quadratic form generators (circular arc, parabolic, hyperbolic, etc.). The metal thickness, however, is limited and some limitations on material properties come into play. The material must be relatively thin and must have good ductility so it will flow properly during the forming process. The thickness of the material can be increased somewhat and materials with relatively low ductility (such as Inconel) can be used: however, heat must be applied during the spinning processes. Depending on the extent of material flow requirement to fabricate the part, stainless steel including RA330 (which has oxidation and strength characteristics for high 
temperature applications similar to Inconel but with higher ductility) can be spun with thickness of 0.10 to $0.15 "$ ".

Metal spinning is appropriate for both test activities and mass production of combustor parts, particularly chambers and aerodynamic valves of optimum configurations.

For test activities, hard-wood mandrels can be made quickly and at a relatively low cost. These mandrels can be used to spin a few parts. For mass production, however, hard-metal mandrels are required. Thus, for laboratory tests, heating the metal during the spinning process is not a viable option, nevertheless, conventional stainless material with small thickness is adequate for short duration testing of new design configurations.

This approach was, therefore, selected for fabrication of advanced configuration chambers and aerodynamic valves (bare metal). A set of fabrication test runs were made using shapes with quadratic form generators similar to what MTCI anticipates for the combustor chamber. The results were excellent.

3. Refractory Lined Components. In our discussions with the metal spinning shop personnel, it became evident that the mandrel design could be made with both metal spinning and casting of refractory-lined components in mind.

Mandrels for metal spinning could be assembled in a composite mandrel for casting chambers and aerodynamic valves. The convenience of using the metal spinning mandrels for refractory-lined casting is valuable for the test program; however, this would not be a major consideration for manufacturing. Therefore, for the time being, every effort will be made to design the mandrels used for metal spinning such that they can also be used for casting refractory-lined components to the extent possible.

For large tail pipes and chambers of units above $30 \mathrm{MMBtu} / \mathrm{hr}$, refractory lining using bricks and castable refractories would be necessary. The use of castable refractory for chambers and tail pipes is expected to be limited to the smaller range of industrial retrofit combustors in the size range from 3 to $15 \mathrm{MMBtu} / \mathrm{hr}$ firing rate.

MTCI believes that it is important to address the above mentioned issues early in the program so as to evolve a commercial configuration combustor technology that is also manufacturable at a reasonable cost with sufficient design flexibility for optimized performance.

\subsection{CONFIGURATION OPTIMIZATION TESTING}

During this period, exploratory testing at 1-1.5 MMBtu/hr on the modified Grandforks combustor was completed and tests using the modified Hanby chamber design were initiated. These configurations are shown in Figure 4-4. These tests are intended to provide data and test experience with these new chamber designs and to provide the basis for an optimized chamber design for the 


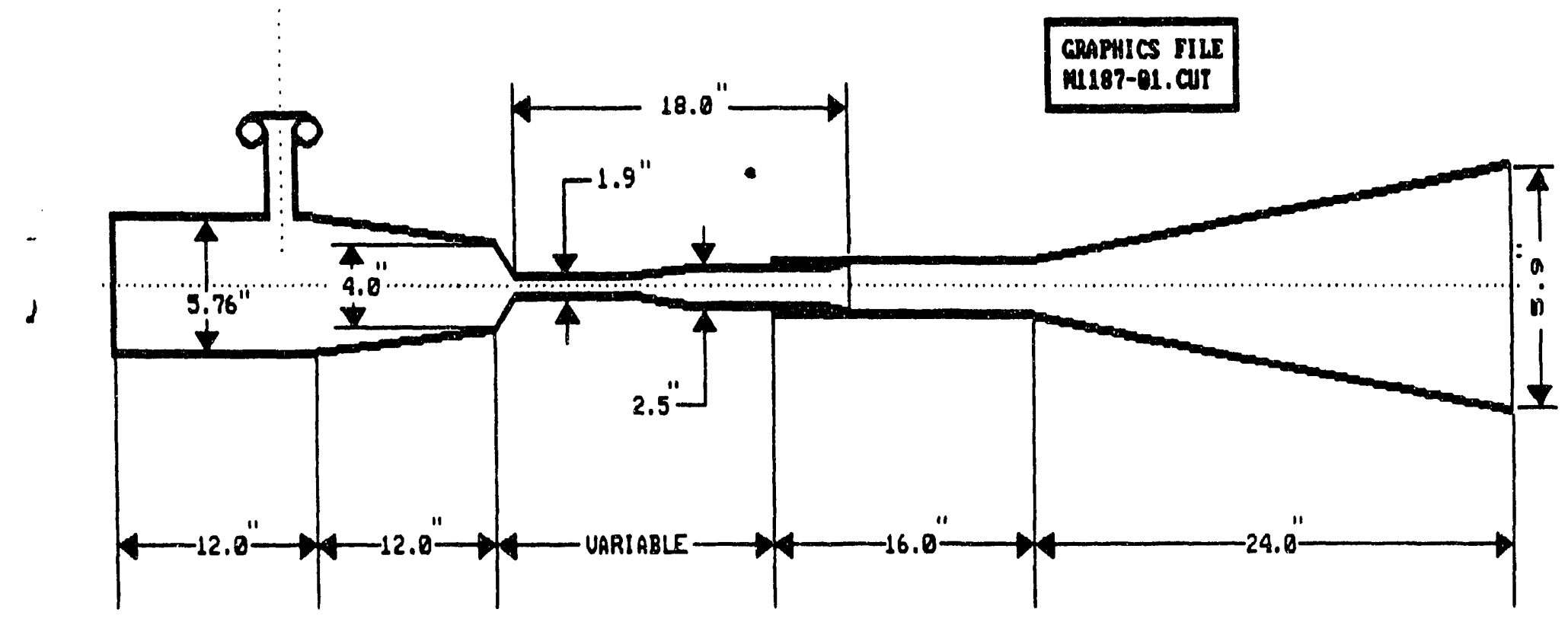

A. MODIFIED GRANFORKS DESIGN

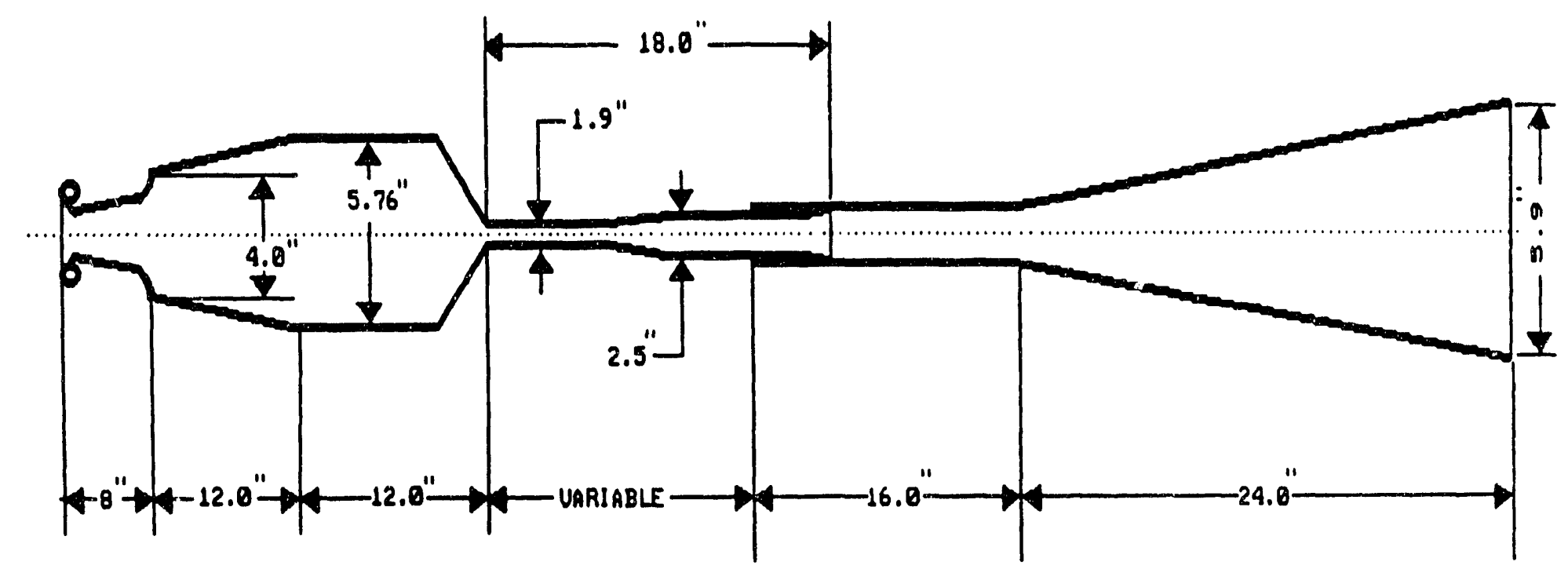

B. MODIFIED HANBY DESIGN

PIGURB 4-4: REY CHAMBER DESIGN 
commercial configuration units. Tests with the modified Hanby design included resonance tube cooling by second-stage combustion air (Figure 4-5).

Developmental testing focused on the modified Grandforks combustor tests. Of particular interest is a concept which was tested for fuel conditioning and feed phasing of fuel injection in the combustion chamber. The concept employed is known as phased coal injector and is shown in Figure 4-6.

The volume of the feed chamber was approximately one-tenth the volume of the combustion chamber and was coupled to the chamber through a 1" port located behind the aerodynamic valve as shown in the figure. The resistance of the 1" port together with the small volume (capacitance) of the feed chamber did not noticeably affect the resonance of the Helmholtz combustor. Nevertheless, during the combustor exhaust stroke hot gases from the combustion chamber rushed into the feed chamber and preheated the coal under substoichiometric air conditions. During the air intake stroke, the combustion chamber pressure drops causing the flow to reverse between the feed chamber and the combustion chamber. This provided for a phased coal injector which "inhales" coal with the feed air simultaneously with the intake portion of the combustor cycle.

Under certain test conditions, this concept appeared to intensify the pressure oscillations per Btu/hr of coal fired. This is usually lower for coal than for natural gas (and for natural gas as compared to propane). It is not clear if this is entirely due to the fuel preheat or due to the automated phasing in fuel injection with the combustor's cycle.

Most of the testing conducted was with the modified Hanby design pulse combustor with expanding tail pipe as shown Figure 4-7. In this modified Hanby configuration, autoaspiration of air was achieved with a 1.875" diameter venturi as the flow diode (Figure 4-8) in the aeradynamic valve, and the tail pipe length was varied between 63" to $70^{\prime \prime}$. When coal feed was started, the chamber temperature climbed from about $1978^{\circ} \mathrm{F}$ to over $2400^{\circ} \mathrm{F}$ (which was the limit of the Type $K$ thermocouple that was used for measurement). The frequency was in the vicinity of 67 to $70 \mathrm{~Hz}$. The small variation of frequency resulted from variations in the gas temperature in the combustor.

Coal combustion increased the pressure boost and the dynamic pressure oscillation in the combustor indicating sufficient heat release in phase with the dynamic pressure oscillation in the modified Hanby combustion chamber. Coal feed was implemented using an eductor system (Figure 4-9) with a screw feeder metering the coal into the eductor system funnel. The coal flow metered into the eductor funnel by the screw feeder possessed periodic changes in flow rate. This was reflected in the variation of the dynamic pressure amplitude. The frequency of the coal feed variation was in the order of two cycles per second; therefore, it did not couple with the resonant operating frequency of the combustor. This test condition, however, provided excellent verification of the combustor's load following capability. The heat release rate, as evident by the variation of the dynamic pressure amplitude variation and the combustor's sound pressure level, responded faithfully to the periodically in the coal feed. The latter was due to the characteristics of the screw feeder used to feed the coal into the eductor funnel. 


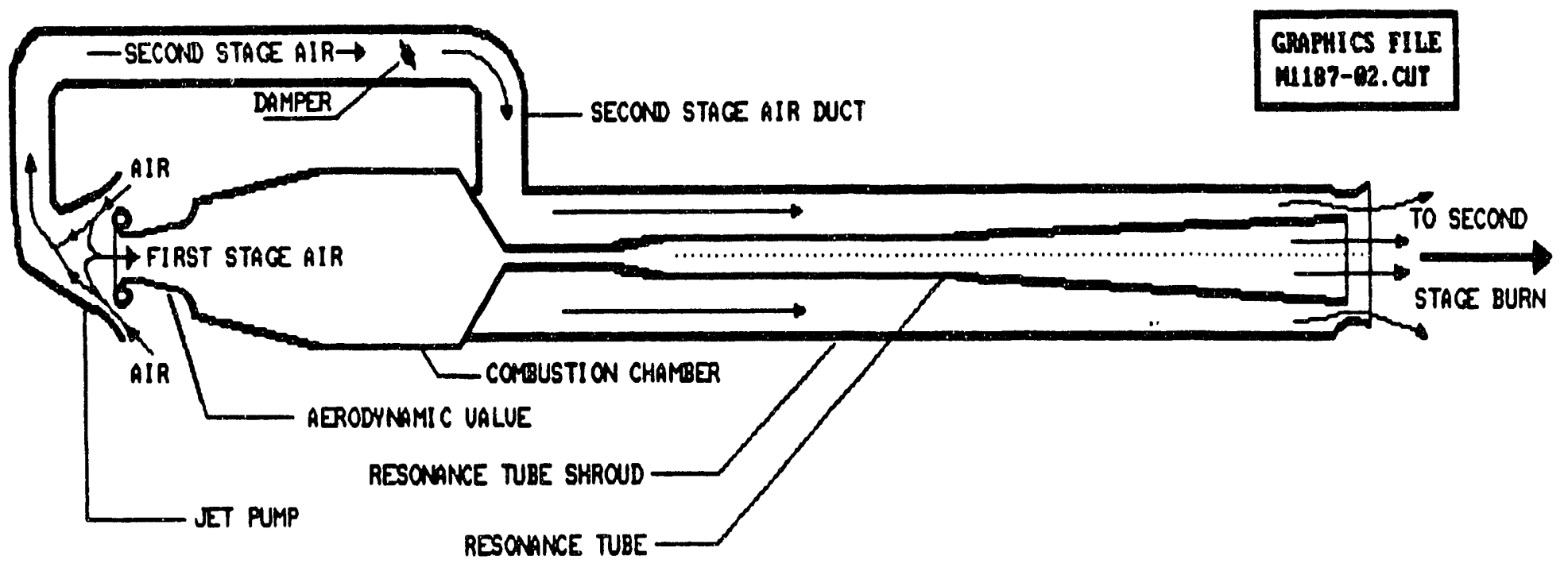

PIGURE 4-5: RESONANCE TUBE COOLIRG SCERTE 


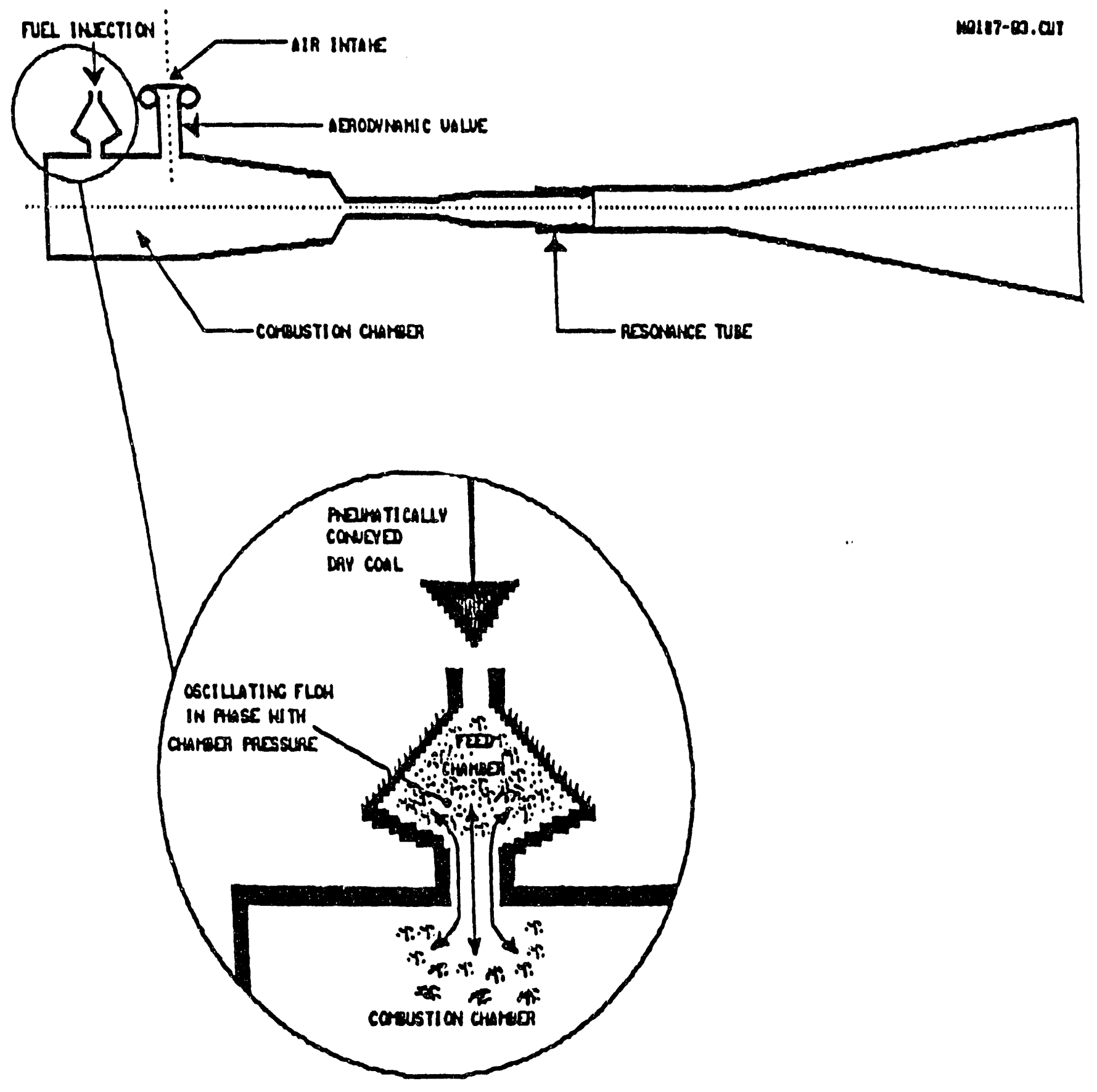

FIGURE 4-6: PRASED COAL INJECTOR 
Cowples Iile

muser-n.01)

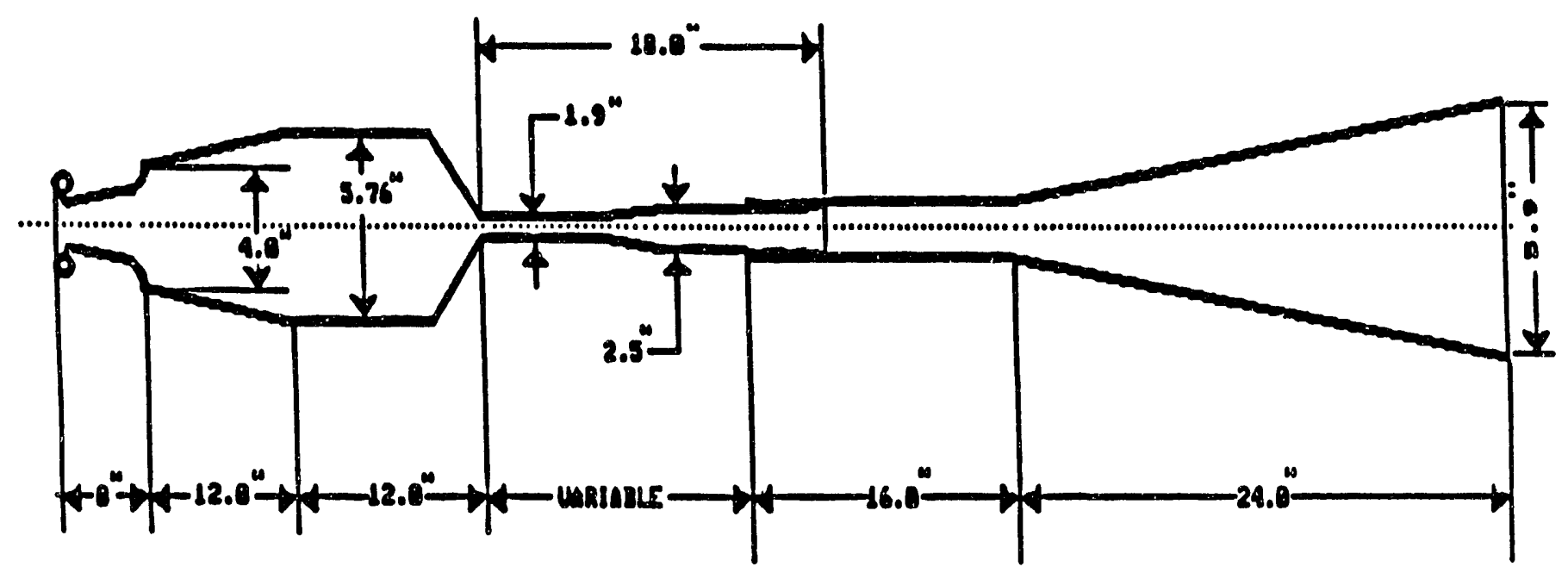

PIGURE 4-7: MODIFIED RANBY DESIGN PULSE COABUSTOR 
confilc जil

mos87-0.4.018

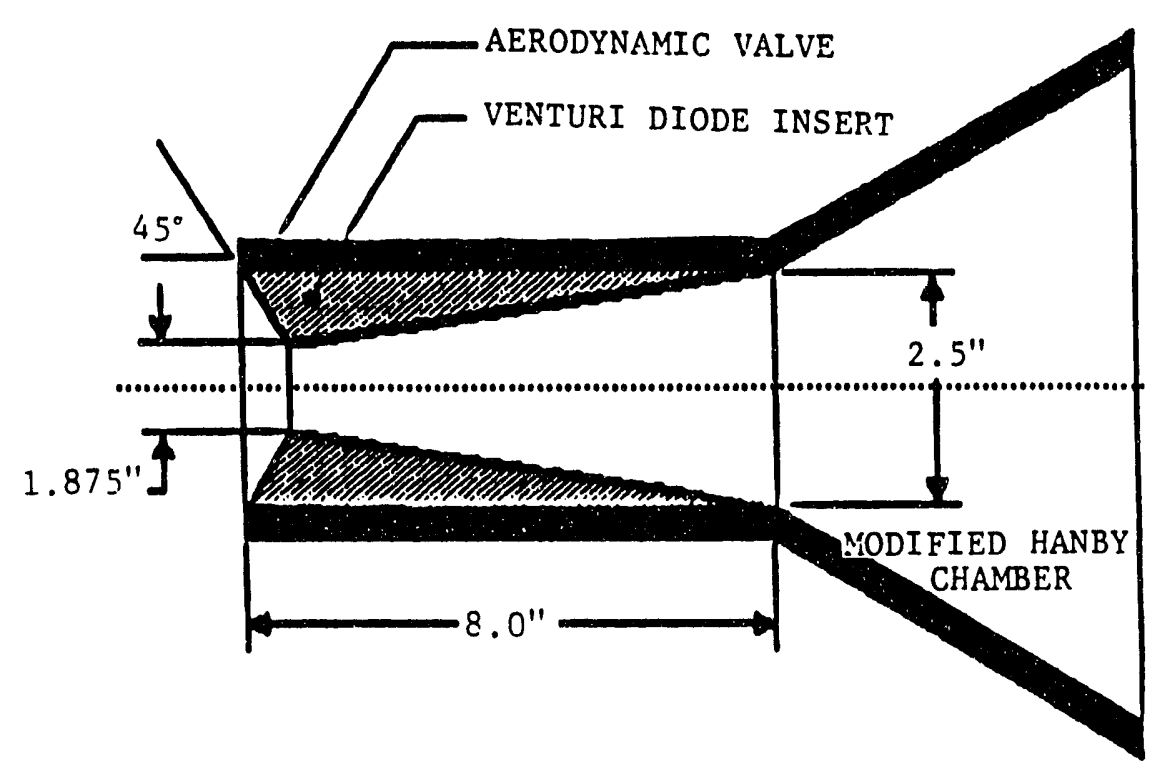

PIGURE 4-8: VENTURI DIODE IASERT 


\section{onvilas rits \\ Mast-6s.an}

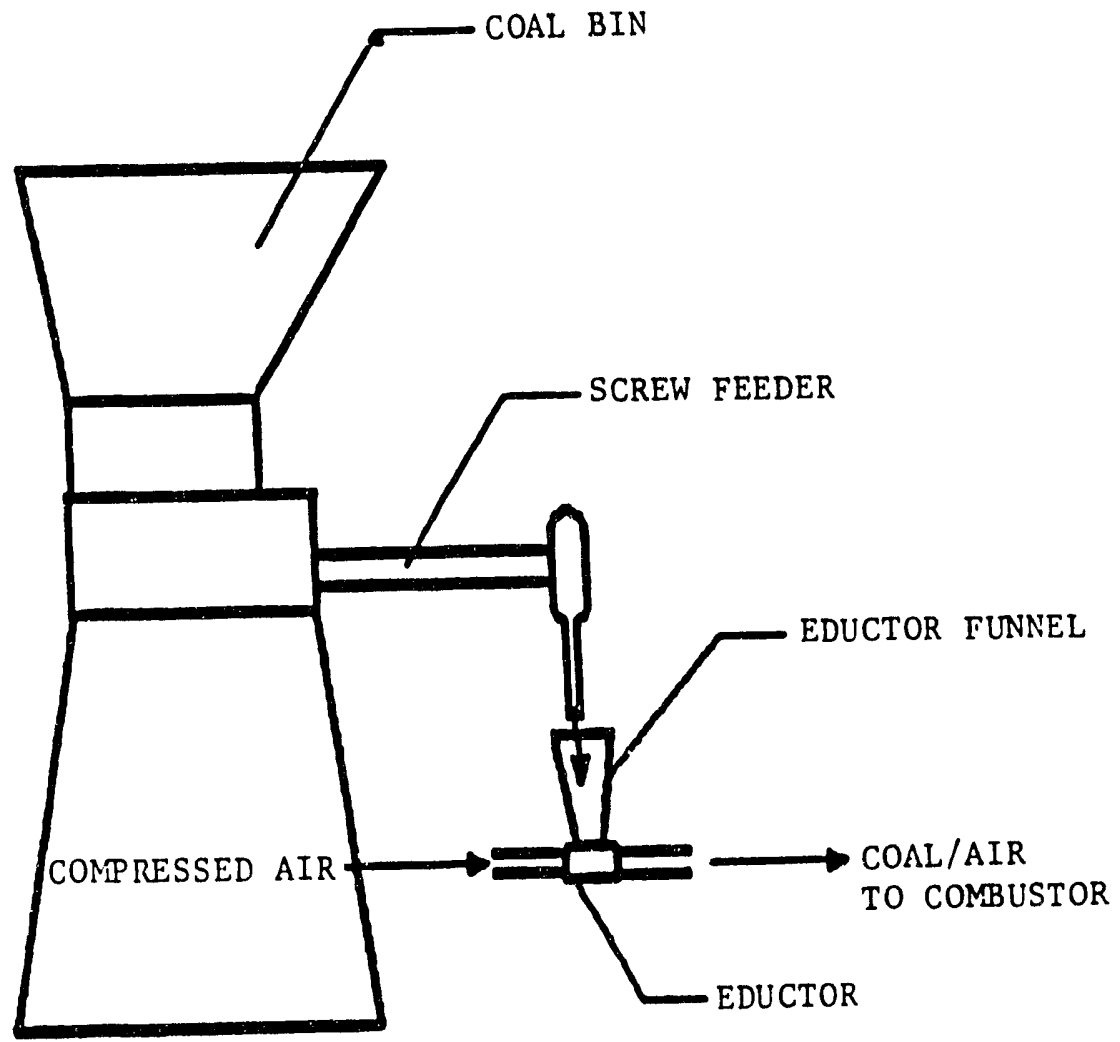

FIGURE 4-9: COAL FBED STSTEM

1

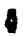


SECTION 5.0

\section{PLANNED ACTIVITY FOR THE NEXT QUARTER}

Configuration optimization on the advanced chamber designs will continue. Data reduction and analysis will also be initiated and data from the experimental work during the past quarter will be evaluated. System modifications for optimization will also be initiated based on the evaluation of the advanced combustor design tests.

One objective for the next period will be to investigate the optimum combustor orientation and tailpipe configuration to provide better control of slag buildup within the combustion system. In addition, a tandem design concept will be implemented to provide a more effective phasing of fuel with combustor pulsing. A facility modification to provide better control of emissions from the laboratory-scale testing will also be addressed in order to eliminate the quench spray cooler and baghouse. This should also provide additional margins of safety for test operations. 

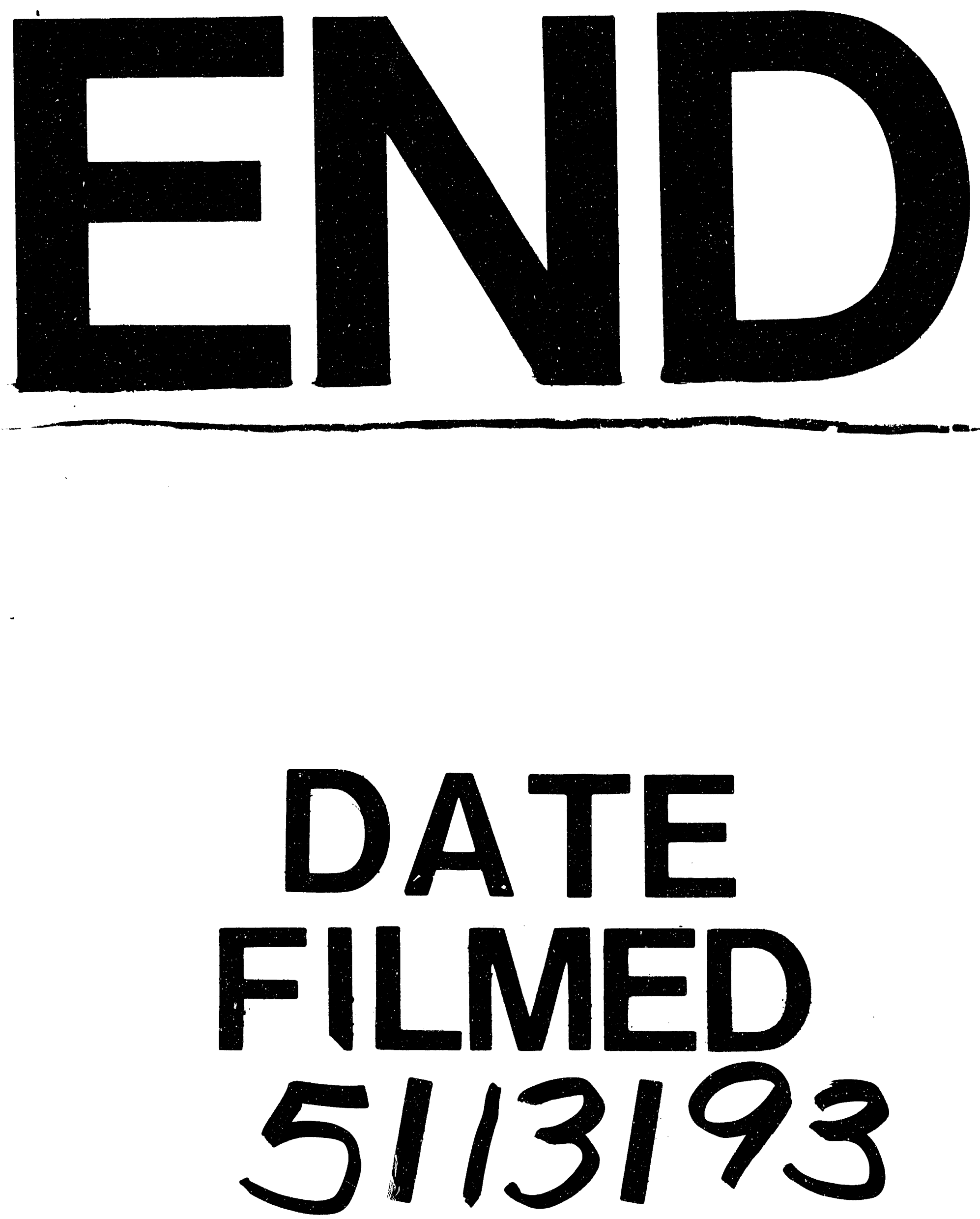
